\title{
Exploring the Antecedents of Mobile Application Usage in the Context of English Learning
}

\author{
Yi-Ting Wang \\ Ling Tung University \\ yw7yw7k@gmail.com
}

\author{
Kuan-Yu Lin \\ Ling Tung University \\ ntustmislab@gmail.com
}

\author{
Travis K. Huang \\ Ling Tung University \\ travisk.huang@gmail.com
}

\begin{abstract}
With the popularization of wireless network and mobile technology, integration of technology into teaching has gradually become indispensable in teaching and learning. In order to probe into the factors influencing learners' continued use of English Learning Apps (ELAPPs), this study uses the Expectation-Confirmation Theory (practical viewpoint) as the theoretical basis for development of research model and combines the Flow Theory (hedonic viewpoint) to propose an integrated research model, thereby exploring the factors that influence learners continued use of ELAPPs and explaining why people continued use ELAPPs. In this study, an online questionnaire was conducted. A total of 289 valid samples were collected and analyzed using a structural equation modeling (SEM) approach. The results of the study show that user satisfaction, perceived usefulness, and flow experience play a significant role in the learners' continued use of ELAPP services. Among others, the flow experience is an important factor that influences the learner's continued use of ELAPPs. In addition, the study also found that perceived skills and perceived challenges have a positive impact on learners' flow experience, showing that in the context of mobile learning-oriented information systems, learners generate flow perception only when they are able to challenge the use of the content of teaching materials in the learning process. The implications of these findings are discussed.
\end{abstract}

\section{Introduction}

E-Learning involves teaching with digital technologies to enable learners to obtain experts' or teachers' wise imparting in order to learn and further promote the access to, as well as the dissemination, preservation and management of such professional knowledge through networks and computer-assisted learning environments and mechanisms without being restricted to a particular period of time or places [1].
With the proliferation of wireless networks and mobile technologies, the integration of mobile technology into English learning has become an indispensable teaching and learning tool for both teachers and students [2][3][4]. Because of lightness and portability of mobile products, the number of students carrying smart phones or tablets has increased. Many mobile-assisted language learning tools have been springing up, especially in the field of language learning (e.g. ELAPP). ELAPP provides learners with the convenience of self-study anytime and anywhere after school, so that e-learning can be performed in nonclassroom areas as well. ELAPP is helpful in mobileassisted language learning. ELAPP will become an effective English learning tool in vocabulary learning, reading, writing, and speaking [5][6][7]. Many studies [6][7] also pointed out that mobile technology (e.g., ELAPP) could effectively enhance learners' learning motivation and learning effectiveness, further helping learners improve their English proficiency. It is learned from the foregoing studies that students' learning by continually using information technology is related to their positive learning experience. In view of this, the study will explore the factors that influence users' continued use of ELAPP.

With respect to the analysis of the use of information technology, the research in mobile technology in recent years has tended to introduce the Expectation-Confirmation Theory (ECT) into its research context [8][9][10], and the research shows that the user's expectation confirmation will positively influence the individual's satisfaction with the use of mobile technology and thus lead to continued use. The ECT theory not only applies to users' purchase intention, technology adaptation and new technology services, but also extends to online learning research. For example, scholars [11][12] based upon ECT theory, extended the research framework to explore students' use of information technology in online learning. However, the ECT theory emphasizes the exploration of people's intention to continually use information 
technology based on practical viewpoint (such as confirmation and perceived usefulness) while it seldom discusses the impact on continued usage intention based upon hedonic viewpoint (such as perceived enjoyment) [12][13][14]. In the past, researchers mainly measured the factors influencing users' continued usage intention from a pragmatic point of view when examining the application of information technology in teaching contexts while ignoring recreational learning experiences [11][13][14]. Alraimi et al. [15] found that learners' pleasant feelings help increase the motivation of students' learning by using information technology, thereby using them continually.

Lin et al. [3] pointed out that the use of information technology in the English learning environment ought not only to take into account the practical aspects of the information system, but also the entertainment factor which is one of the most important aspects. In exploring the user's delightful experience, the past research has often been discussed using the Flow Theory [16][17] which was proposed by the psychologist, Csikszentmihalyi [18] who believed that flow experiences were joyful. People in such a state would be completely immersed in the activities they are engaged in, and their attention would be concentrated as well. Pleasant experiences tended to make people experience joyful experience again even without incentives. Huang et al. [19] found that flow experience came from the individual challenge and ability balance, with confidence and ability to complete the challenge. Therefore, this study believes that when using information technology and consciously considering a balance between challenges and abilities, a sense of full participation will come and thus the continued use increases.

As mentioned previously, the past studies of continued usage behaviors, in most of the cases, have been based on the Expectation-Confirmation Theory from a practical viewpoint, and considered the effects of confirmation, usefulness and satisfaction on continued use. However, ECT lacks a hedonic view, ignoring the psychological factors affecting continued use. This study therefore considers that the use of information technology in aiding learning should take into account joyful learning experience to be integrated in the design of teaching materials. It not only makes students feel that learning is pleasant but also increases the motivation of students' learning by using information technology like ELAPP. As mentioned above, this study uses the Expectation-Confirmation Theory (practical viewpoint) as the theoretical basis of the research model, combining the Flow Theory (hedonic viewpoint) as well as proposing an integrated research model to explore the factors that impact learners on the continued use of ELAPP.

\section{Research Purpose and Approaches}

In recent years, the expectation-confirmation model from a practical viewpoint has often been introduced to research contexts in which the users' usage behavior of mobile technology is explored [8][9][10]. The research shows that the user's expectation confirmation will positively affect the individual's satisfaction with the use of mobile technology, thereby facilitating continued use. A body of research [8][10][11] shows that the three dimensions - the degree of confirmation, perceived usefulness and user satisfaction - are important factors affecting individuals' continued use of information systems. Chow and Shi [11] believed that students' continued use of the learning system should be discussed from the perspective of ETC. The results of the study show that the degree of confirmation is the key factor influencing students' satisfaction and continued use. Therefore, being based on the ECT theory, this study explores the user's intention to continually use English mobile Apps in practical aspects.

The mobile application is not just a type of practical oriented application software, but an entertainment-oriented application [5]. The advancement in students' intrinsic motivation can influence continued learning, of which hedonic is one of the important factors that influence continued use. In the exploration of joyful experience of intrinsic motivation, past research has often used the Flow Theory for such exploration [5][17]. The Flow Theory used to be applied to life, work, sports, leisure and other fields. Recently, the Internet has developed rapidly, and scholars have begun to use the Flow Theory to discuss the interaction among consumers, computers, information systems, or networks, etc. [16][20]. Many activities on the Internet are accompanied by flow experiences [21][22], such as searching on the Internet [23], online communication [24], and online games [21]. Using the Flow Theory in the study of online learning, we also found that enjoying flow experience is a very important factor in continued learning [25]. Therefore, this study uses the Flow Theory as the basis to explore the antecedents and consequences from a hedonic viewpoint on users' flow experience in English learning mobile Apps.

\section{Research model and hypotheses}

Next, we will discuss the development of our research model and hypotheses based on the Expectation-Confirmation Theory and the Flow Theory. 
Figure 2 illustrates the research model proposed in this study.

\subsection{Expectation-Confirmation Theory}

The Expectation-Confirmation Theory was proposed by Oliver [26] in the marketing field and derived from the extended cognitive model of satisfaction. Such a theory suggests that consumers' satisfaction with the product or service will affect their repurchase intention. The degree of satisfaction with the product or service was determined by the prepurchase expectations, the performance of use after purchase and the comparison of the two. It was believed that there were three psychological states in the process that resulted in the expectationconfirmation performance which were: expected positive disconfirmation (perceived performance exceeds expectations), expectation confirmation (perceived performance is equivalent to expectations), or expected negative disconfirmation (perceived performance is lower than expectations). Consumers' comparison results will affect the level of satisfaction, which will further affect the repurchase or reuse intention.

Bhattacherjee [27] believes that the decision of continued adoption of information system made by users is similar to the decision-making behavior of consumers for repurchasing. Therefore, he further extends the ETC theory and proposes the "IS Continuance Model" as shown in Figure 1, and introduces ETC to the resource management domain. In its research model, the "perceived usefulness" of the technology acceptance model was added to replace the perceived performance used, and this concept was defined as the expectation after experience, mainly because the user's initial perceived usefulness for the new system was low and subject to being confirmed. However, after using the system for a period of time, the user gradually confirms the benefits brought about by the system and will gradually adjust the initial expectation to form a latter expectation after the matter (i.e. perceived usefulness). The study found that users' satisfaction and perceived usefulness after the use of information system would affect the user's continued usage intention. Next, the user's degree of confirmation and perceived usefulness after the use of information system would positively affect the user satisfaction. Finally, the user's degree of confirmation after the use of information system would affect the user's perceived usefulness.

Many studies have also confirmed that the three dimensions of degree of confirmation, perceived usefulness and satisfaction are important factors affecting the individual's continued usage intention of information systems. As a result, the ECT theory is widely used in new technology services. For example, Chow and Shi [11] believe that the students' continued use of the learning system should be explored from the ETC perspective. The research results show that the degree of confirmation is the key factor impacting students' satisfaction and continued use. Oghuma et al. [10] found that users' continued usage intention of mobile communication software was positively correlated with confirmation, perceived usefulness and satisfaction. Thus, it is assumed that confirmation, perceived usefulness and satisfaction will affect the user's continued usage intention of the product or service. Scholars [28][29] further pointed out that user satisfaction had a strong influence on users' behavioral intention. On the basis of the above, this study suggests that the learners' degree of confirmation and perceived usefulness in the use of English learning application software will affect their satisfaction with mobile application software and thus their continued usage intention. Therefore, this study proposes the following hypotheses:

[H1] User satisfaction positively affects learners' intention to continue using ELAPPs.

[H2a] Perceived usefulness positively affects learners' intention to continue using ELAPPs.

[H2b] Perceived usefulness positively affects learners' satisfaction.

[H3a] Degree of learners' confirmation positively affects their satisfaction.

[H3b] Degree of learners' confirmation positively affects perceived usefulness.

\subsection{Flow experience and users' intention to continue using ELAPPs}

The Flow Theory proposed by Csikszentmihalyi [18] studied why people felt happy and considered flow a joyful experience, which was used in measuring the feeling of pleasure. Csikszentmihalyi [18] defined the flow experience as a common mode of experience that people enter when they are strongly focused on certain activities and ignore the surroundings. This model has the following characteristics: clear goal, unambiguous feedback, challenge-skill balance, actionawareness merging, concentration on the task and hand, sense of control, loss of self-consciousness, altered sense of time, and the autotelic experience [30]. Webster et al. [31] further pointed out that flow is a temporary and subjective experience as well as a reason why people are willing to continue to engage in certain activities. When people focus on certain activities, filter other unimportant perceptions, and devote themselves to the activities, they are entering a flow state. 


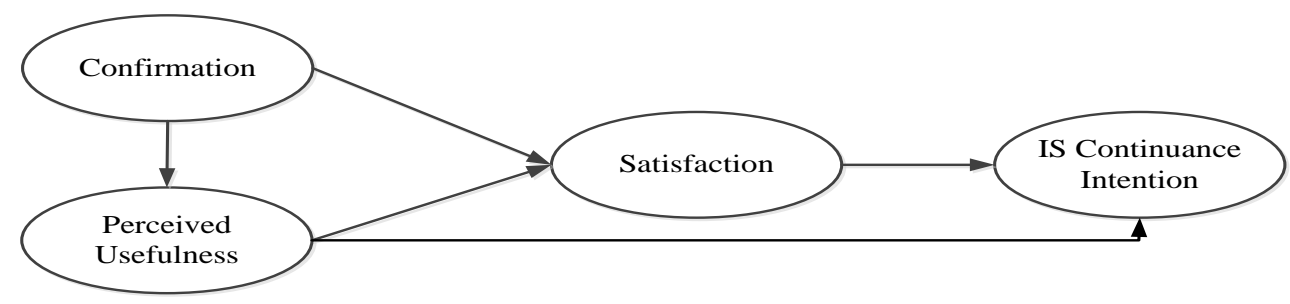

Figure 1. Theory of Expectation-Confirmation

Flow is the joyful experience. When people are engaged in an activity, they have a clear goal to make them aware of what they are doing and enjoy the process of achieving the goal [30]. Therefore, the clear goal is one of the conditions creating flow experience. In the learning aspect, learning knowledge and skills is a very important goal. The past research [32] found that skills and challenges were two important factors in the Flow Theory. When skills are greater than challenges, users will feel bored; while challenges are greater than skills, users will feel anxious. Only when the user's skills are comparable to the standard will they be in a flow state. In other words, flow experience comes from individual's balance between challenge and ability, with confidence and competence to complete the challenge. To students, ELAPP is a challenging mobile learning tool. When the user is consciously aware that his skills are equivalent to the challenges of the teaching materials content, they feel flow.

This study considers ELAPP a match of task and capacity. We divide it into two parts: perceived skill and perceived challenge. Ozkara et al. [33] pointed out that the more the users became controllable and competent in the game system challenge, the better they were able to enhance their enjoyable experience. The use of many information technologies is accompanied by flow experiences that will affect user satisfaction and usage behavior [20]. Therefore, this study argues that when learners use ELAPP for interesting or meaningful purposes, if they gain a flow experience in the activity, they would appreciate the entertainment needs they acquire and be satisfied, thereby leading to the continued usage intention. Thus this study assumes:

[H4a] Flow experience positively affects learners' intention to continue using ELAPP.

[H4b] Flow experience with ELAPP positively affects learners' satisfaction.

[H5] Perceived skill of ELAPP positively affects learners' flow experience.

[H6] Perceived challenge positively affects learners' flow experience.

\section{Measurement}

The research model includes seven factors. Each factor was measured by a multiple-item scale. To ensure content validity, the items selected for the constructs were largely adapted from prior research. The items were slightly modified to suit the context of English APP. The items of continued intention to use were modified from Davis [34]. Items addressing confirmation and user satisfaction were adapted from Hsu and Lin [9] and items for measuring perceived usefulness and perceived skill were modified from $\mathrm{Lu}$ et al. [35] and Ooi et al. [14]. Finally, items measuring perceived challenge and flow experience were modified from Huang et al. [19]. All items were measured by using a five-point Likert scale, ranging from strongly disagree (1) to strongly agree (5). Table 1 lists all of the survey items used to measure each construct and descriptive statistics

\section{Results}

5.1Data collection and sampling

The research object of this study was intended for the users of English mobile application software. According to the statistics of Big Data Group [36], the top 10 most popular APP categories in Google Play, among which "education" ranks first, and English learning APP accounts for 6 of them. We chose Super Word King (http://superwordking.wixsite.com/home) to be the research object. This mobile application software mainly provides learners with games for English learning. SimilarWeb [37] points out that Super Word King is currently the most popular gamebased English mobile application software in Taiwan. For these reasons, we selected Super word king users in Taiwan to be the subjects of this study. We used a questionnaire survey to test our theoretical model. The invitation messages were posted on forum associated with English APP sites. The effective sample size included $116(40.1 \%)$ males and 173 (59.9\%) females. The highest proportion (40.9\%) were aged between 19 and $25.36 .8 \%$ were aged under $18,15.2 \%$ were aged between 26 and 35, and $7.1 \%$ were aged 36 and over. 


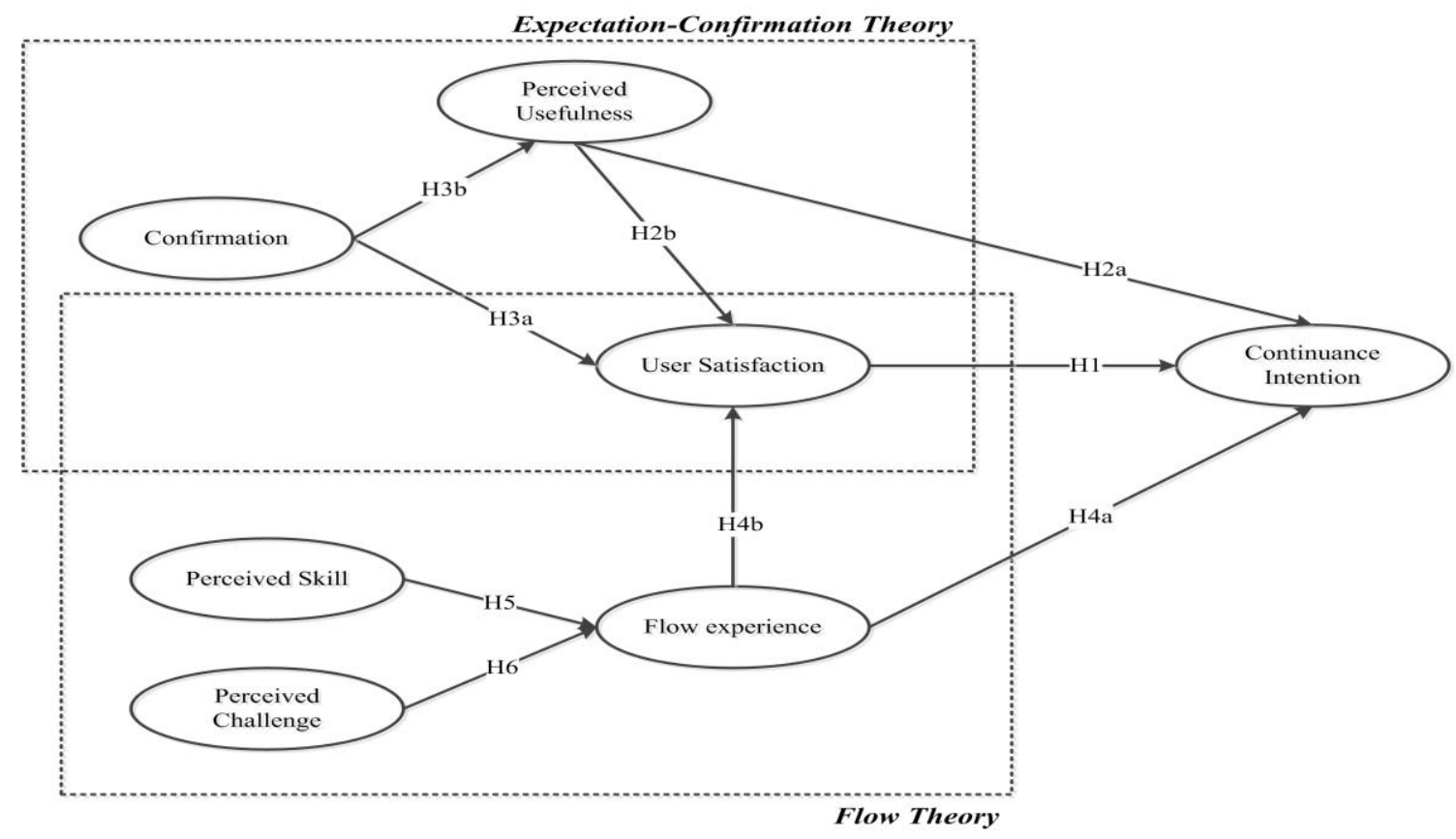

Figure 2. The Research Model

\subsection{Analysis of the measurement assessment}

The measurement model was further assessed for construct reliability and validity. First, reliability analysis was measured using Cronbach's alpha and composite reliability (CR) model to assess the model's internal consistency. All Cronbach's alpha coefficients ranged from 0.84 to 0.88 , exceeding the acceptable value of 0.70 [38]. The $\mathrm{CR}$ of each dimension was greater than 0.8, higher than Fornell and Larcker's [39] proposed threshold value of 0.7. In terms of convergent validity, Bagozzi and $\mathrm{Yi}$ [40] proposed three measurement standards: (1) all indicator factor loadings should exceed 0.5, (2) CR should exceed 0.7, and (3) the average variance extracted (AVE) of each dimension should exceed 0.5. As shown in Table 1, factor loadings of all items in the measurement model of this study exceeded 0.7. CR of constructs ranged from 0.83 to 0.88 and AVE ranged from 0.63 to 0.71 . Therefore, the measurement model featured adequate reliability and convergent validity.

\subsection{Analysis of the structural model}

We conducted structural equation modelling analysis by using AMOS21.0 to test the structural model. The model fit criteria suggested by model provided evidence of a good model fit $\left(\chi^{2} / \mathrm{df}=2.31\right.$, $\mathrm{GFI}=0.88, \mathrm{AGFI}=0.85, \mathrm{NFI}=0.91, \mathrm{CFI}=0.95$, and RMSEA $=0.067)$. Figure 3 displays the standardized coefficients path, path significances, and variance explained $\left(\mathrm{R}^{2}\right)$ by each path. The results showed that the English APP behavior was predominantly determined by user satisfaction $(\beta=0.31, p<0.01)$, perceived usefulness $(\beta=0.26, \mathrm{p}<0.05)$, and flow experience $(\beta=0.40, p<0.001)$, supporting H1, H2a and $\mathrm{H} 4 \mathrm{a}$, respectively. Perceived usefulness $(\beta=0.50$, $\mathrm{p}<0.001)$, confirmation $(\beta=0.36, p<0.001)$, and flow experience $(\beta=0.18, p<0.01)$ were also found to have significant positive association with user satisfaction, thus supporting $\mathrm{H} 2 \mathrm{a}, \mathrm{H} 3 \mathrm{a}$ and $\mathrm{H} 4 \mathrm{~b}$, respectively. The results also showed that perceived usefulness $(\beta=0.77, \mathrm{p}<0.001)$ was significantly affected by confirmation, thus, H3b was supported. Finally, perceived skill and perceived challenge significantly affected the flow experience of users. Therefore, H5 and H6 were supported. Regarding the hypothesis tests, all paths were significant at the level of $\mathrm{p}<0.05$ or above. Hence, H1 to H6 were supported. The variance explained $\left(\mathrm{R}^{2}\right)$ of continued intention to use English APP was 74\%, that of user satisfaction was $85 \%$, that of perceived usefulness was $60 \%$ and that of flow experience was $59 \%$.

\section{Discussion and conclusions}

This study aims at the users of the English mobile application software (Super word king), and it tries to find out crucial reasons why people continue to use English learning application software from the perspective of the Expectation-Confirmation theory and the Flow Theory. The findings are discussed below. 
Table 1. Item analysis with factor loadings, CR, and AVE.

\begin{tabular}{|c|c|c|c|c|}
\hline Construct and items & $\begin{array}{l}\text { Factor } \\
\text { loadings }\end{array}$ & $\mathrm{CR}$ & AVE & Alpha \\
\hline Confirmation (CO) & & 0.83 & 0.63 & 0.84 \\
\hline 1. My experience with using this English Learning App was better than I expected. & 0.74 & & & \\
\hline $\begin{array}{l}\text { 2. The service level or function provided by this English Learning App was better } \\
\text { than I expected }\end{array}$ & 0.81 & & & \\
\hline $\begin{array}{l}\text { 3. Overall, most of my expectations from using this English Learning App were } \\
\text { confirmed. }\end{array}$ & 0.82 & & & \\
\hline Perceived usefulness (PU) & & 0.86 & 0.68 & 0.86 \\
\hline 1. Using this English Learning App would be convenient for me to learn. & 0.80 & & & \\
\hline 2. English Learning App improves my learning efficiency. & 0.84 & & & \\
\hline 3. English Learning App increases my chances of getting more knowledge. & 0.83 & & & \\
\hline Satisfaction (SA) & & 0.84 & 0.64 & 0.84 \\
\hline 1. Using English Learning App makes me feel very satisfied. & 0.84 & & & \\
\hline 2. Using English Learning App makes me feel very contented. & 0.80 & & & \\
\hline 3. Using English Learning App makes me feel very delighted. & 0.76 & & & \\
\hline Perceived Skill (SK) & & 0.88 & 0.71 & 0.88 \\
\hline 1. Using English Learning App is entirely within my control. & 0.78 & & & \\
\hline 2. I have the knowledge and ability to use English Learning App. & 0.85 & & & \\
\hline 3. I am able to skillfully use English Learning App. & 0.90 & & & \\
\hline Perceived Challenge $(\mathrm{CH})$ & & 0.85 & 0.66 & 0.85 \\
\hline 1. Using English Learning App challenges me. & 0.86 & & & \\
\hline 2. Using English Learning App challenges me to the best of my ability. & 0.83 & & & \\
\hline 3. Using English Learning App provides a good test of my skills. & 0.74 & & & \\
\hline Flow experience $(F E)$ & & 0.86 & 0.66 & 0.86 \\
\hline 1. I frequently experience flow when playing English Learning App. & 0.74 & & & \\
\hline 2. In general, I have frequently experienced flow when I play English Learning & 0.83 & & & \\
\hline App. & 0.87 & & & \\
\hline $\begin{array}{l}\text { 3. Most of the time when I use English Learning App I feel I am experiencing } \\
\text { flow. }\end{array}$ & & & & \\
\hline Continued intention to use (CIU) & & 0.86 & 0.67 & 0.86 \\
\hline 1. I will continue using English Learning App. & 0.85 & & & \\
\hline 2. I will continue using English Learning App in the future. & 0.83 & & & \\
\hline 3. I will recommend my friends use English Learning App. & 0.77 & & & \\
\hline
\end{tabular}

Figure 3 illustrates the research results. Regarding the factors affecting continued use, the study found that user satisfaction, perceived usefulness, and flow experience were the main factors in people's continued use of English mobile application software. Among others, the flow experience had the most significant impact on users' continued use of English mobile application software. The results of this study are consistent with the past research [41][42]. In the context of game-based learning-oriented information systems, flow experience plays an important role Therefore, for service providers who learn situational mobile application software, the increase of the gamebased curriculum design can really drive the learners' entertaining feelings about the learning system, thereby attracting the learners' continued usage intention of the mobile application software. What comes next is the effect of satisfaction on learners' use of mobile application software. The results of this study also confirm the viewpoint of scholars [14] that if people are satisfied with information technology that will positively influence their behavioral intention. Users' satisfaction with the English mobile application software will increase their continued usage intention. Finally, the perceived usefulness in this study is mainly to measure the usefulness of English mobile communication software in learning efficiency. The results of the study show that perceived usefulness has a positive impact on learners' continued usage intention of English mobile application software. Thus, if learners perceive that the English mobile application software improves the efficiency of learning, it will enhance its perceived usefulness and further affect its usage behavior. 


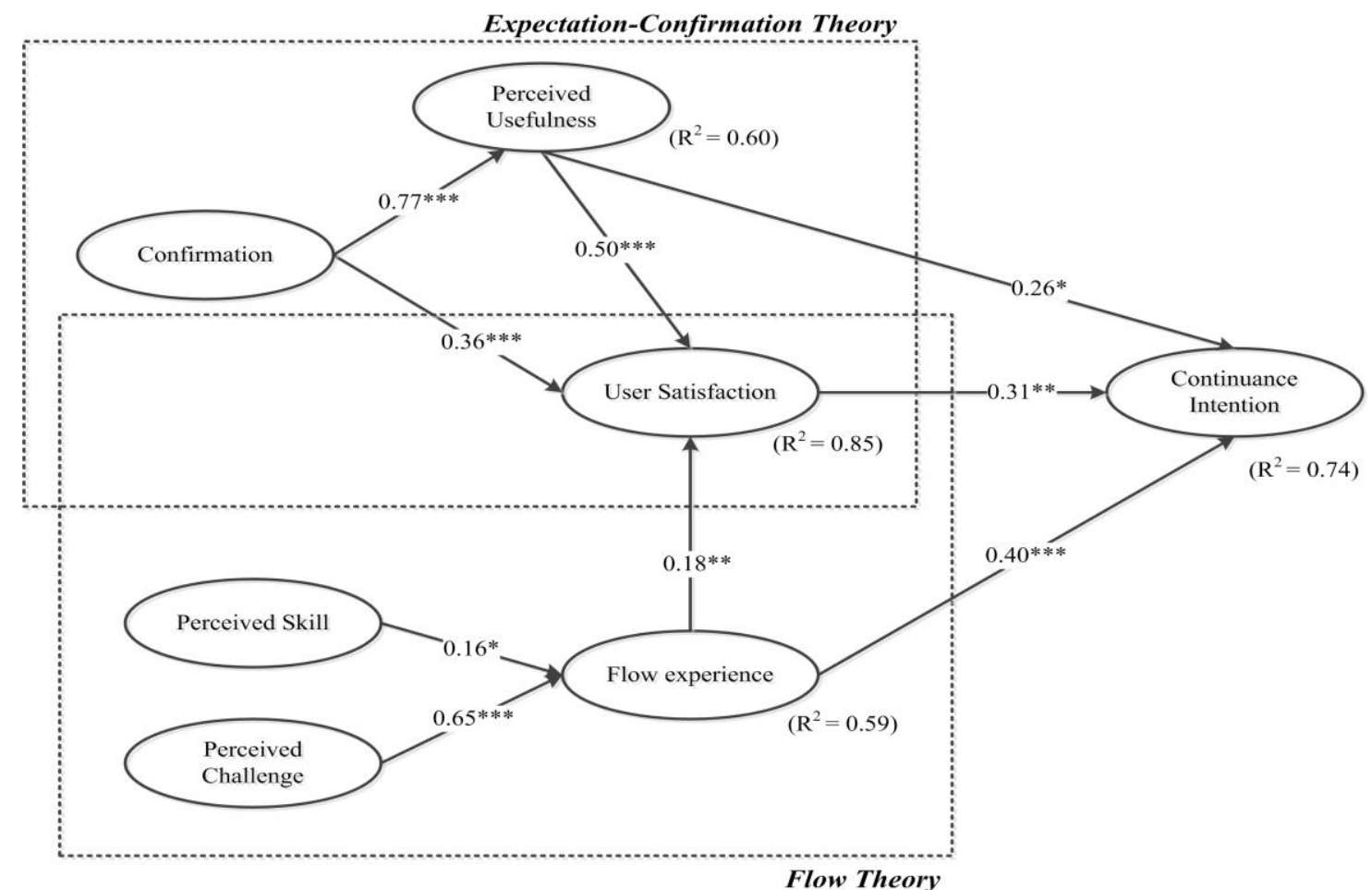

Figure 3. Structural model results (Note. ${ }^{* * *} \mathrm{p}<0.001,{ }^{* *} \mathrm{p}<0.01,{ }^{*} \mathrm{p}<0.05$, ns $=$ not significant)

Perceived usefulness, confirmation, and flow experience have a direct positive effect on satisfaction in terms of influencing user satisfaction. It shows that in the mobile learning context, learners believe that the English mobile application software has the convenient service of timeliness, allowing them to learn and gain knowledge quickly at anytime, and thus enhancing the usefulness. Next, learners compare the expectations of using the English mobile application software with the performance after use, and the confirmed results do affect whether the learners are satisfied. Such results are consistent with the findings of the ECT proposed by Bhattacherjee [27]. Finally, learners' flow experience in English mobile applications software will positively affect their satisfaction. As referred to by previous studies, the use of many information technologies will be accompanied by flow experiences that further affect learners' satisfaction and usage behavior [20]. Therefore, if learners can gain flow experience while doing an activity, their entertainment needs would be satisfied.

In terms of the impact on the flow experience, both perceived skills and perceived challenges affect flow experience, which is consistent with previous scholars' research perspectives. Flow experience comes from the individual's challenge and ability balance, and selfconfidence and competence can complete challenges [32]. Consequently, when learners are able to challenge their own ability by using the content of the materials in the learning process, they can feel the sense of flow.

The results of this study have several important academic implications. First, based upon the Expectation-Confirmation Theory, this study probes into the feelings driven by learners' satisfaction with English mobile application software accompanied by the Flow Theory and develops an integrated model structure. First, it discusses the factors affecting people's continued use of English mobile applications. Second, past research mainly explored how the online learning system influences learners' usage behavior through the expectation confirmation model [13]. Scholars suggest that except for confirming whether the usage system in the teaching information system usage context can bring about advantages, the influence of the system on continuance intention from the hedonic viewpoint is rarely discussed [13][14]. Therefore, this study added entertaining learning experiences so as to more fully predict users' intention to continue using English mobile applications software. Third, this study uses perceived skills and perceived challenge factors to form the learners' flow experience brought by English mobile application software. These factors respectively affect the flow experience of learners. Finally, this research model has presented its great potential, and it can indeed predict the user's continued usage intention of English mobile 
application software. Such research results may serve as a reference for follow-up research.

Several implications for mobile application service practitioners can be drawn from this study. First, the results show that flow experience has direct and significant influence on the learners' continued use of English mobile application software. Most teachers apply MALL to the teaching design and still consider the user's learning performance, ignoring the importance of creating joyful learning experience. Therefore, in terms of enhancing learning, the teaching design should take into account the joyful learning, so that students feel that learning is enjoyable and thus increasing students' motivation to continue using ELAPP learning. Second, the results of the study show that skills and challenges are two important factors in the Flow Theory. When skills are greater than challenges, users are bored; while challenges are greater than skills, users are anxious. Only when the user's skills are comparable to the standard will it create a flow state. Kiili [43] specified that the online game-based learning with a challenge design of clear goals and learner motivation will better enable learners to achieve good learning outcomes (such as knowledge acquisition or preservation and management). Game challenge is the driving force behind the game, which stimulates learners' curiosity and intrinsic motivation, even improves learning outcomes. In addition, a sense of control in the game (such as perceived skills) affects the learner's intrinsic motivation in the digital learning environment [44]. In other words, the higher the perceived skills, the better the learning pace and rate of progress the learner can predominate, which in turn leads to flow experience. Therefore, this study argues that digital teaching material designers who are able to design textbooks from the perspective of flow experience, as well as using interactive software to introduce the application of textbook design will strengthen the pleasure of learning and increase the continued usage intention of English mobile application software. Third, this study also found that user satisfaction was an important factor affecting the individual's continued usage intention of English mobile application software. The degree of confirmation and perceived usefulness are the major antecedents affecting learner satisfaction with ELAPP among others. These results provide the practitioners with important information showing that in the context of teaching-oriented information systems, learners have greater satisfaction when the experience after use is higher than the expectations before use. On the other hand, the convenience, learning efficiency, and opportunities to gain more knowledge provided by ELAPP to enhance learners' perceived usefulness are very important. Therefore, while sustaining learner relationships, the digital teaching material designers should give great care upon learners' reception of perceived usefulness in the usage process of ELAPP. Learners' good reception will increase the satisfaction, thereby being relatively less prone to replacing the ELAPP, and as a result they will continue to use the service in learning, and accordingly the service provider gains more profitable opportunities.

Despite its valuable findings and implications, this study contains some limitations. First, the implications are based on a single study with samples in Taiwan. Research should use caution when generalizing the findings to other ELAPP learning situations. Future studies should conduct research in cross-cultural contexts to investigate and compare the differences in antecedents of continued usage intentions. Second, regarding our research methodology, we used a quantitative statistical research model. Online questionnaires were used to collect information, and news of the online survey was widely advertised on a variety of websites. The purpose of this advertisement was to increase sample diversity and avoid excessive bias caused by too few sample attributes, thereby skewing the results. However, self-selection bias may well be present in such online surveys. We propose that future research could use a quality assisted quantitative viewpoint to support such research. Finally, two crucial antecedents of ELAPP use are proposed, namely the factor of expectation confirmation (confirmation and perceived usefulness) and the factor of flow experience (perceived skill and perceived challenge); however, it is impossible to use them to explain all attitudes towards using ELAPP. It is recommended that future research incorporate other constructs in the models, such as system characteristics, individual personalities, and cultural factors, to offer superior information for comprehensive explanation and prediction in terms of the behavior involved in using learning-oriented information systems.

\section{Acknowledgments}

The authors thank the editor and anonymous reviewers for their comments and suggestions. This study was supported by a grant from the Ministry of Science and Technology: project number MOST-1062410-H-275-007-.

\section{References}

[1] Y. H. Tsai, C. H. Lin, J. C. Hong, and K. H. Tai, "The effects of metacognition on online learning interest and continuance to learn with MOOCs", Computers \& Education, 121(1), 2018, pp.18-29. 
[2] D. Chun, R. Kern, and B. Smith, "Technology in language use, language teaching, and language learning", The Modern Language Journal, 100(1), 2016, pp.64-80.

[3] C.H. Lin, Y. Zhang, and B. Zheng, "The roles of learning strategies and motivation in online language learning: A structural equation modeling analysis", Computers \& Education, 113(1), 2017, pp.75-85.

[4] S. A. Nikou, and A. A. Economides, "Mobile-based assessment: Investigating the factors that influence behavioral intention to use", Computers \& Education, 109(1), 2017, pp.56-73.

[5] A. Fernandez-Lopez, M. J. Rodriguez-Fortiz, M. L. Rodriguez-Almendros, and M. J. Martinez-Segura, "Mobile learning technology based on iOS devices to support students with special education needs", Computers \& Education, 61(1), 2013, pp.77-90.

[6] J. C. Hong, M. Y. Hwang, K. H. Tai, and Y. L. Chen, "Using calibration to enhance students' self-confidence in English vocabulary learning relevant to their judgment of over-confidence and predicted by smartphone self-efficacy and English learning anxiety", Computers \& Education, 72(3), 2014, pp.313-322.

[7] Q. Wu, "Designing a smartphone app to teach English (L2) vocabulary", Computers \& Education, 85(6), 2015, pp. 170-179.

[8] J. Cho, "The impact of post-adoption beliefs on the continued use of health apps", International Journal of Medical Informatics, 87(1), 2016, pp.75-83.

[9] C. L. Hsu, and J. C. C. Lin, "What drives purchase intention for paid mobile apps? - An expectation confirmation model with perceived value", Electronic Commerce Research and Applications, 14(1), 2015, pp.45-57. [10] A. P. Oghuma, C. F. Libaque-Saenz, S. F. Wong, and Y. Chang, "An expectation-confirmation model of continuance intention to use mobile instant messaging", Telematics and Informatics, 33(1), 2016, pp.34-47.

[11] W. S. Chow, and S. Shi, "Investigating Students' Satisfaction and Continuance Intention Toward E-Learning: An Extension Of The Expectation-Confirmation Model", Procedia - Social and Behavioral Sciences, 141, 2014, pp. 1145-1149.

[12] M. Chang, and A. H. K. Yuen, "Student continuance of learning management system use: A longitudinal exploration", Computers \& Education, 120, 2018, pp.241253.

[13] G. Dağhan, and B. Akkoyunlu, "Modeling the continuance usage intention of online learning environments", 60(1), 2016, pp. 198-211.

[14] K. B. Ooi, J. J. Hew, and V. H. Lee, "Could the mobile and social perspectives of mobile social learning platforms motivate learners to learn continuously?", Computers \& Education, 120, 2018, pp.127-145.

[15] K. M. Alraimi, H. Zo, and A. P. Ciganek, "Understanding the MOOCs continuance: The role of openness and reputation", Computers \& Education, 80(1), 2015, pp.28-38.

[16] I. E. Millat, F. J. M. Lopez, R. H. Garcia, A. Mesequer, and I. R. Ardura, "Modelling students' flow experiences in an online learning environment", Computers \& Education, 71(1), 2014, pp.111-123.
[17] S. H. Liu, H. L. Liao, and J. A. Pratt, "Impact of media richness and flow on e-learning technology acceptance", Computers \& Education, 52 (3), 2009, pp.599-607.

[18] M. Csikszentmihalyi, Beyond boredom and anxiety. San Francisco: Jossey-Bass, 1975.

[19] H. C. Huang, L. S. Huang, Y. J. Chou, and C. I. Teng, "Influence of temperament and character on online gamer loyalty: Perspectives from personality and flow theories", Computers in Human Behavior, 70(1), 2017, pp.398-406.

[20] C. C. Chang, "Examining users' intention to continue using social network games: A flow experience perspective", Telematics and Informatics, 30(4), 2013, pp.311-321.

[21] T. Novak, D. Hoffman, Y. Yung, "Measuring the customer experience in on-line environments: a structural modeling approach", Marketing Science 19 (1), 2000, pp.2242.

[22] I. Ha, Y. Yoon, and M. Choi, "Determinants of adoption of mobile games under mobile broadband wireless access environment", Information \& Management, 44, pp.276-286.

[23] D. H. Shin, and W. Y. Kim,"Applying the technology acceptance model and flow theory to cyworld user behavior: Implication of the Web 2.0 user acceptance", CyberPsychology \& Behavior, 11, pp. 378-82.

[24] H. Liu, H. Chu, Q. Huang, and X. Chen, "Enhancing the flow experience of consumers in China through Interpersonal interaction in social commerce", Computers in Human Behavior, 58, 2016, pp.306-314.

[25] L-A. P. Ho, and T-H. Kuo, "How can one amplify the effect of e-learning? An examination of high-tech employees' computer attitude and flow experience", Computers in Human Behavior, 26, 2010, pp.23-31.

[26] R. L. Oliver, "A cognitive model of the antecedents and consequences of satisfaction decisions", Journal of Marketing Research, 17(4), 1980, pp.460-469.

[27] A. Bhattacherjee, "An empirical analysis of the antecedents of electronic commerce service continuance", Decision Support Systems, 32(2), 2001, pp.201-214.

[28] C. F. Chen, and F. S. Chen, "Experience quality, perceived value, satisfaction and behavioral intentions for heritage tourists", Tourism Management, 31(1), 2010, pp.2935.

[29] M. H. Hsu, C. M. Chang, and L. W. "Chuang, Understanding the determinants of online repeat purchase intention and moderating role of habit: The case of online group-buying in Taiwan", International Journal of Information Management, 35(1), 2015, 45-56.

[30] M. Csikszentmihalyi, The domain of creativity. In M. A. Runco \& R. S. Albert (Eds.). Theories of creativity (pp. 190212). Newbury Park, C.A: Sage, 1990.

[31] J. Webster, L. K. Trevino and L. Ryan, "The dimensionality and correlates of flow in human-computer interactions", Computers in Human Behavior, 9(4), 1993, pp.411-426.

[32] Y. M. Guo, and M. S. Poole, "Antecedents of flow in online shopping: a test of alternative models", Information Systems Journal, 19(4), 2009, pp.369-390.

[33] B. Y. Ozkara, M. Ozmen, and J. W. Kim, "Exploring the relationship between information satisfaction and flow in the context of consumers' online search", Computers in Human Behavior, 63, 2006, pp.844-859. 
[34] F. Davis, "Perceived usefulness, perceived ease of use, and user acceptance of information technology", MIS Quarterly, 13(3), 1989, pp.319-340.

[35] Y. Lu, T. Zhou, and B. Wang, "Exploring Chinese users' acceptance of instant messaging using the theory of planned behavior, the technology acceptance model, and the flow theory", Computers in Human Behavior, 25, 2009, pp.29-39.

[36] Big Data Group, Google Play Announces 10 Most Popular App Types, 2017. Available from http://group.dailyview.tw/

[37] SimilarWeb, Mobile APP Ranking, Available at https:// www.similarweb.com/apps/top/google/store-rank/tw/educati on/top-free, 2018.

[38] J. C. Nunnally, Psychometric Theory, McGraw Hill, New York, NY, 1978.

[39] C. Fornell, and D. F. Larcker, "Evaluating structural equation models with unobservable variables and measurement error", Journal of Marketing Research, 18(1), 1981, pp. 39-50.

[40] R. P. Bagozzi, and Y. Yi, "On the evaluation of structural equation models", Journal of Academy of Marking Science, 16(2), 1988, pp. 74-94.

[41] W. Admiraal, J. Huizenga, S. Akkerman, and G. T. Dam, "The concept of flow in collaborative game-based learning", Computers in Human Behavior, 27(3), 2011, pp.1185-1194.

[42] C. C. Chang, C. Liang, P. N. Chou, and G. Y. Lin, "Is game-based learning better in flow experience and various types of cognitive load than non-game-based learning? Perspective from multimedia and media richness", Computers in Human Behavior, 71, 2017, pp.218-227.

[43] K. Kiili, "Digital game-based learning: Towards an experiential gaming model", The Internet and higher education, 8(1), 2005, pp.13-24.

[44] M. P. J. Habgood, S. E. Ainsworth, and S. Benford, "Endogenous fantasy and learning in digital games", Simulation and Gaming, 36(4), 2005, pp.483-498. 